\title{
PRIMENA INTERNETA U KOMUNIKACIJI TELEFONSKIH KORISNIKA U RURALNIM OBLASTIMA - MODIFIKACIJA POSTUPKA PRENOSA SIGNALIZACIJE
}

\author{
Aleksandar Lebl, Dagan Mitić, Žarko Markov \\ IRITEL a.d., Srbija
}

\begin{abstract}
:
Rad prikazuje kako se primenom Interneta može ostvariti govorna telefonska komunikacija korisnika u oblastima bez dovoljno razvijene telekomunikacione infrastrukture. Analiziraju se načini prenosa telefonskih signala preko Interneta, a posebno načini slanja telefonske signalizacije. Na kraju se prikazuje kako je poboljšan metod slanja signalizacionog kriterijuma identifikacije pozivajućeg pretplatnika preko Interneta u odnosu na ono što je omogućeno Internetskim preporukama. Analizirane su performanse novog postupka u pogledu kašnjenja u prenosu, potrebnog kapaciteta za prenos signala preko Interneta i verovatnoće greške u prenosu.
\end{abstract}

\section{Key words:}

telefonski korisnici, ruralne oblasti, telefonska signalizacija, gejtvej, identifikacija pozivajućeg pretplatnika.

\section{UVOD}

Savremeni razvoj telekomunikacija doneo je sa sobom sve veću primenu Interneta. Internet je prodro u sve oblasti ljudskog života: obrazovanje, poslovanje, privredne delatnosti, itd. Jedan bitan element primene Interneta danas je i komunikacija među ljudima.

Kada govorimo o savremenim sistemima komunikacije, obično prvo pomislimo na raznovrsne servise, koji su dostupni korisnicima u razvijenim oblastima, razvijenim zemljama, ili gradskim sredinama. Međutim, još uvek postoje mnoge nerazvijene zemlje, ili nerazvijene, ruralne oblasti $u$, inače, naprednijim zemljama, gde problem predstavlja obična, govorna komunikacija među ljudima. U tim oblastima nedostaje kablovska mreža, koja bi omogućila klasičnu telefonsku komunikaciju. Takođe, klasični telefonski komutacioni sistemi su udaljeni od korisnika, tako da je neophodna i izgradnja telefonskih centrala, a ne samo kablovske mreže. Pošto se radi o retko naseljenim oblastima, često se postavlja i pitanje ekonomske isplativosti izgradnje kompletne telekomunikacione infrastrukture.

U ovakvim slučajevima primena Interneta predstavlja jedno moguće rešenje. $U$ prvom delu ovog rada bavimo se načinima primene Interneta u ostvarivanju telefonskih funkcija u nerazvijenim zemljama i nerazvijenim ruralnim oblastima. Postupci, potrebni da bi se ostvarile ove funkcije prilično davno su razrađeni u literaturi i definisani međunarodnim preporukama, na bazi čega postoje i mnoga primenjena rešenja. Ovi postupci nisu uključivali postupke slanja nekih signalizacionih kriterijuma klasične telefonije preko Interneta. Jedan od signala, čije slanje nije bilo definisano, je signal identifikacije pozivajućeg pretplatnika (caller ID). Zato se u drugom delu rada govori o tome kako smo definisali slanje ovog signala preko Interneta.

\section{MOGUĆI NAČINI OSTVARIVANJA TELEFONSKE VEZE PREKO INTERNETA}

Problem ostvarivanja telefonske veze u nerazvijenim područjima nosi sa sobom problem premošćavanja velikih prostora, u kojima ne postoji razvijena telekomunikaciona infrastruktura, niti se ona lako može izgraditi. $\mathrm{Na}$ Sl.1, prikazani su mogući načini rešavanja ovih problema primenom Interneta.

Prema strukturi na Sl.1a, telefonski korisnici u udaljenoj oblasti spojeni su na telefonsku centralu (Telefonska centrala 1) [1]. Ovo može biti sasvim mala telefonska centrala, ukoliko je posmatrana oblast slabo naseljena (eventualno kućna centrala). Signali na izlazu ove telefonske centrale formiraju digitalni vremenski multipleks (time division multiplex - TDM). Planirano je da se ovakva telefonska centrala povezuje sa drugim telefonskim centralama preko digitalnih multipleksnih linkova (na primer, E1 linkovi). Zbog značajne prostorne udaljenosti do druge telefonske centrale, klasični E1 linkovi zamenjuju se IP linkovima. Oni mogu biti realizovani optičkim linkovima ili, verovatnije, bežičnim linkovima. Da bi ostvario prelaz sa E1 linkova na IP linkove, u blizini telefonske centrale 1 postavlja se gejtvej (gateway - GW), koji obavlja potrebnu konverziju signala u oba smera. U smeru od telefonske centrale, GW paketizuje E1 signale u IP pakete, formirajući TDM over IP signal (TDMoIP). U obrnutom smeru vrši se depaketizacija TDMoIP signala u TDM signale. 

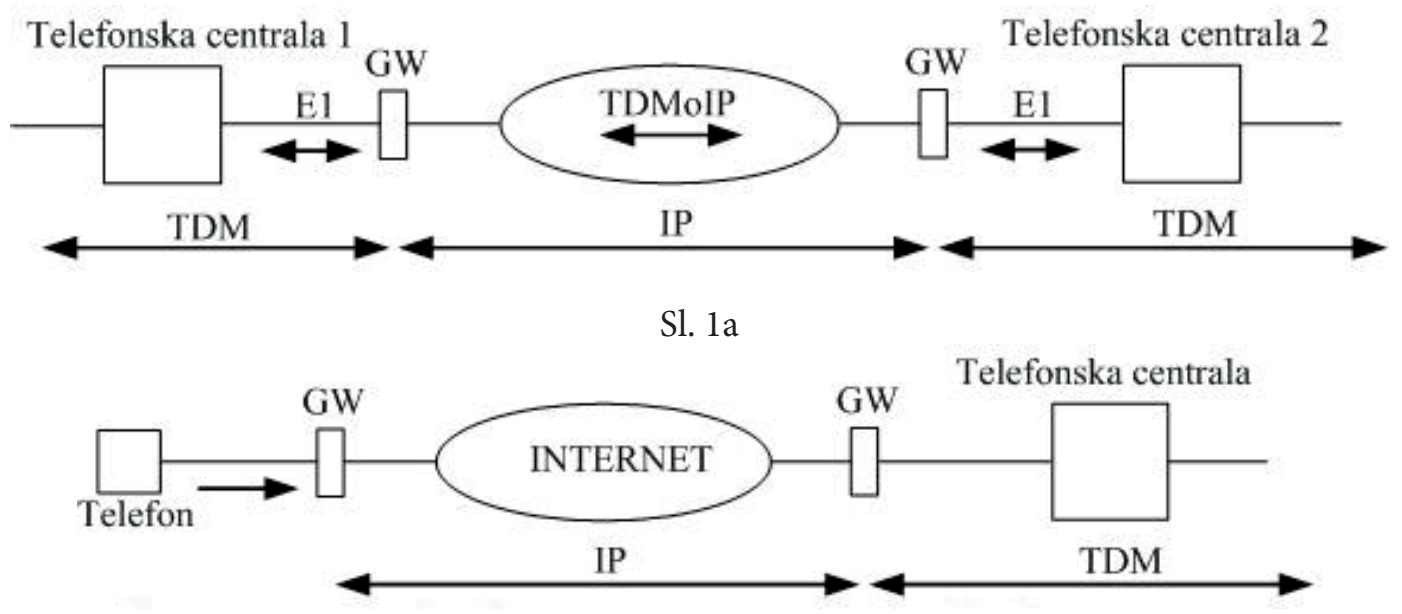

Sl. $1 \mathrm{~b}$

Sl. 1. Mogući načini ostvarivanja telefonske veze posredstvom Interne

Na drugoj strani IP linka postoji, takođe, GW, čiji je zadatak da E1 signale vrati u svoj izvorni oblik, kako bi se oni koristili u telefonskoj centrali (Telefonska centrala 2).

Drugi mogući scenario priključivanja udaljenih telefonskih korisnika prikazan je na Sl.1b, [1], [2]. U ovom slučaju telefonska centrala ne postoji u blizini telefonskih korisnika, tako da se u blizini telefonskog priključka (ili više njih) nalazi GW. U ovom slučaju GW vrši paketizaciju digitalizovanih govornih signala sa pretplatničke linije. $\mathrm{Na}$ njegovom izlazu formira se IP link, kojim se paketizovani signali šalju prema telefonskoj centrali. Na drugoj strani IP linka nalzi se GW, koji depaketizuje govorne signale i vraća ih u oblik, koji može da koristi pretplatnički priključak u telefonskoj centrali.

\section{POSTUPAK SLANJA SIGNALIZACIONIH KRITERIJUMA PREKO INTERNETA}

Pouzdan i jasno definisan postupak prenosa signalizacionih kriterijuma predstavlja važan element u ostvarivanju svih telefonskih veza. Samim tim, posebna pažnja posvećuje se tehnikama slanja signalizacionih kriterijuma preko Interneta.

Zavisno od toga koji se od dva mrežna scenarija sa Sl.1, primenjuje, različiti signalizacioni kriterijumi se šalju preko Interneta. U slučaju primene scenarija sa Sl.1a, preko Interneta se šalju linijska i registarska signalizacija između telefonskih centrala (na primer, jednobitska i dvobitska linijska signalizacija i registarska signalizacija). U slučaju primene scenarija sa Sl.1b, preko Interneta se šalju telefonski signali (birački impulsi, tonski signali).

Pod prenosom signalizacionih kriterijuma u Internet mreži mogu se podrazumevati sledeći postupci [1]:

- direktno paketizovanje TDM signala uključuje u sebi i paketizovanje signalizacije, tako da se, kada se u kanalima E1 linka šalju signalizacioni kriterijumi, vrši njihovo paketizovanje u TDMoIP signal. $\mathrm{U}$ ovom slučaju isti put se koristi za slanje govornog signala i signalizacije;

- prenos klasičnih telefonskih signala podrazumeva učaurenje telefonskih signala u Internetske paketi- zovane poruke i njihovo slanje, sa ili bez tumačenja značenja signala u paketskom delu mreže;

- paketizovanje mrežnih signalizacionih kriterijuma (signala koji se šalju između telefonskih centrala) i njihovo slanje preko Interneta posebnim paketskim ili IP trunk-om;

- prenos telefonskih signala između telekomunikacione mreže i Internetske mreže, što podrazumeva da GW na sučelju dve mreže ima mogućnost tumačenja značenja pojedinih signala u obe mreže i mogućnost prevođenja signala iz jednoj mreži u signale u drugoj mreži;

- direktno formiranje signala koji se koriste u IP mreži bez da se prvo formiraju signali klasične telefonije, a zatim konvertuju u odgovarajuće IP pakete, u ovom slučaju postoji samo paketska mreža, a TDM (odnosno klasična telefonska mreža) ne postoji.

\section{POSTUPCI PRENOSA TELEFONSKE SIGNALIZACIJE PREKO INTERNETA}

U prenosu telefonske signalizacije preko Interneta koriste se tri osnovna postupka.

Prvi postupak direktno proizlazi iz opisa scenarija prikazanog na Sl.1a. U ovom slučaju paketizuje se kompletan sadržaj E1 linkova, bez ulaženja u tumačenje namene signala u pojedinim kanalima u toku veze. Formira se TDMoIP signal Ako se u kanalu E1 linka trenutno prenose signalizacioni kriterijumi, oni će biti paketizovani u IP pakete i tako preneti do mesta gde se depaketizuju i vraćaju u svoj izvorni oblik. Ovakav način prenosa signalizacije je najbrži, jer na kašnjenje u prenosu utiče samo vreme potrebno za paketizaciju i depaketizaciju signala.

Drugi postupak sastoji se u određivanju svojstava (parametara) signala. Najčešće su to frekvencija (frekvencije) koja (koje) čine signal, nivo signala i trajanje signala. Ako se signalizacioni kriterijum sastoji od nekoliko delova, za svaki deo posebno se određuju frekvencije i trajanje signala. Tako određena svojstva signala prenose se u sklopu IP paketa. Na mestu prijema na izlazu iz IP linka rekonstrui- 
še se signal na osnovu svojih parametara. Ovakav način prenosa je sporiji nego paketizoanje u TDMoIP signal, jer na kašnjenje pored vremena potrebnog za paketizaciju utiče i vreme neophodno da se odrede parametri signala, ali zahteva manji kapacitet na IP linku.

Treći postupak sastoji se u tumačenju značenja signala, odnosno prepoznavanju signala. Kada se prepozna konkretan signal, preko IP linka se prenosi kôd događaja, tj. kod prepoznatog signala. Ovakav način slanja signalizacionih kriterijuma je najsporiji (sporiji od prethodna dva postupka), jer je neophodno da protekne kompletno trajanje jednog perioda signala, da bi se protumačilo njegovo značenje. U pogledu potrebnog kapaciteta IP linka, ovakav način zahteva manji kapacitet nego prethodna dva postupka. Pored toga, prednost ovakvog načina prenosa signalizacionih kriterijuma je što se oni na mestu prijema mogu rekonstruisati u svom nominalnom obliku. Naime, u prethodna dva slučaja na mestu prijema rekonstruisani signal zadržava elemente degradacije svoga kvaliteta unete na predajnom delu telefonske veze (slabljenje, odstupanje detektovane frekvencije signala u odnosu na tačno generisanu, uneti šum). Kada se signali prenose svojim kôdovima događaja, izbegava se ovakva degradacija kvaliteta veze.

Slanju signala preko kodova događaja posvećena je posebna pažnja u ovom radu.

\section{SLANJE SIGNALA IDENTIFIKACIJE POZIVAJUĆEG KORISNIKA PREKO INTERNETA}

Prvi korak u analizi, koju smo sproveli, bio je da se upoznamo sa time koji su telefonski signali definisani da se šalju preko Interneta trećim postupkom (korišćenjem kôdova događaja), kako je to naznačeno u prethodnom poglavlju. Analiza je obuhvatila signale u slučaju primene oba scenarija, kako je to prikazano na Sl.1. Ovi postupci slanja su detaljno prikazani i definisani u RFC preporukama [3], [4], [5]. Uočeno je da ovim preporukama nije definisano slanje signala identifikacije pozivajućeg pretplatnika (callerID - CID) primenom kôdova događaja. Zato smo definisali postupak slanja ovog signala pomoću kôdova događaja. Postupak je primenljiv u slučaju scenarija prikazanog na Sl.1b.

CID signal se formira kao FSK (frequency shift keying) signal [6], [7]. Svaki bit, čija je vrednost 1, koduje se kao signal frekvencije $1300 \mathrm{~Hz}$, dok se bit, čija je vrednost 0 , koduje kao signal frekvencije $2100 \mathrm{~Hz}$. Brzina slanja bitova informacije je 1200 bit/s. CID signal se može slati vezano za pozivni signal (ringing) i u tom slučaju se šalje posle upućivanja prvog pozivnog signala ( $\mathrm{tj}$. $\mathrm{u}$ pauzi između prva dva pozivna signala). Pored toga, može se slati nevezano za pozivni signal. U ovom, drugom, slučaju slanju CID signala prethodi slanje jednog od sledeća tri signala (alerting signal): kratkotrajno slanje pozivnog signala (Ringing Pulse Alerting Signal - RP-AS), slanje specifičnog tonskog signala (Dual Tone Alerting Signal - DT-AS), koji se formira od dve frekvencije (dvotona) ili obrtanje polariteta pretplatničke petlje praćeno dvotonom (line reversal followed by DT-AS - RP+DT-AS).

Preporukama [6], [7] precizno su definisani vremenski odnosi koje moraju da zadovolje CID signali u odnosu na ostale signale sa kojima se zajedno šalju. Ovi neophodni vremenski odnosi moraju ostati zadovoljeni i posle reprodukcije CID u prijemnom GW. O tome smo vodili računa prilikom definisanja novog postupka slanja CID signala preko Interneta.

Slanje CID signala uvek je povezano sa slanjem još jednog signala (pozivnog signala ili alerting signala - AS) i oni tek zajedno imaju potrebno značenje. Ova dva signala možemo prikazati odvojenim kôdovima događaja ili jednim kôdom događaja. U prvom slučaju, na primer, postoji jedan kôd događaja za DT-AS signal i drugi kôd događaja za CID signal. U drugom slučaju jedinstvenim kôdom događaja definiše se slanje DT-AS signala zajedno sa CID signalom.

U Tabeli 1 prikazani su vremenski odnosi između originalnog signala i reprodukovanog signala (maksimalno kašnjenje početka reprodukcije), kao i kašnjenje, koje je potrebno uvesti u prijemnom GW od momenta kada on primi paket poruke vezane za slanje CID signala i od kada bi reprodukcija, praktično, mogla da počne [8]. Podaci su dati posebno za kodovanje sa dva kôda događaja i sa jednim kôdom događaja. Pored situacija u kojima se šalje CID signal, dati su i podaci za slučaj slanja samo pozivnog signala bez CID signala.

Uočljivo je da je maksimalno kašnjenje reprodukcije manje u slučaju kodovanja korišćenjem dva odvojena kôda događaja. S druge strane, potrebno je voditi računa o unošenju potrebnog kašnjenja pri reprodukciji u prijemnom GW, o čemu ne treba voditi računa ako se slanje vrši korišćenjem jedinstvenog kôda događaja.

\section{TABELA 1 VREMENSKI ODNOSI PRI REPRODUKCIJI CID SIGNALA}

\begin{tabular}{|c|c|c|c|c|}
\hline \multirow{2}{*}{ Opis slanja } & \multicolumn{2}{|c|}{$\begin{array}{c}\text { Maksimalno } \\
\text { kašnjenje početka } \\
\text { reprodukcije (ms) }\end{array}$} & $\begin{array}{c}\text { Kašnjenje koje treba } \\
\text { uvesti u prijemnom } \\
\text { gateway-u (ms) }\end{array}$ \\
\cline { 2 - 5 } & $\begin{array}{c}2 \text { kôda } \\
\text { događaja }\end{array}$ & $\begin{array}{c}\text { 1 kôd } \\
\text { događaja }\end{array}$ & $\begin{array}{c}2 \text { kôda } \\
\text { događaja }\end{array}$ & $\begin{array}{c}1 \text { kôd } \\
\text { događaja }\end{array}$ \\
\hline Poziv + CID & 1280 & 4180 & 180 & 0 \\
\hline Samo poziv & 1280 & 3100 & 180 & 0 \\
\hline DT-AS + CID & 1100 & 1690 & 990 & 0 \\
\hline RP-AS + CID & 1180 & 2180 & 880 & 0 \\
\hline LR + DT-AS + CID & 1080 & 1780 & 1080 & 0 \\
\hline
\end{tabular}

$\mathrm{Na}$ Sl.2, prikazana su kašnjenja u reprodukciji signala, koji prethodi CID signalu u funkciji dužine CID poruke i dužine signala sa kojim je CID signal povezan pri svom slanju. Sl.2a, se odnosi na slučaj kada slanje tonskog signala prethodi CID signalu, a Sl.2b, na slučaj kada slanje poziva prethodi CID signalu. Isprekidanom linijom prikazana je vrednost kašnjenja za slučaj kodovanja pomoću dva kôda događaja, dok je punom linijom prikazana vrednost kašnjenja za slučaj kodovanja pomoću dva kôda događaja. Na apscisi je predstavljena zbirna vrednost trajanja CID poruke $\left(t_{m}\right)$ i vremenskog intervala između završetka signala, čije slanje prethodi CID signalu i samog početka CID signala. 


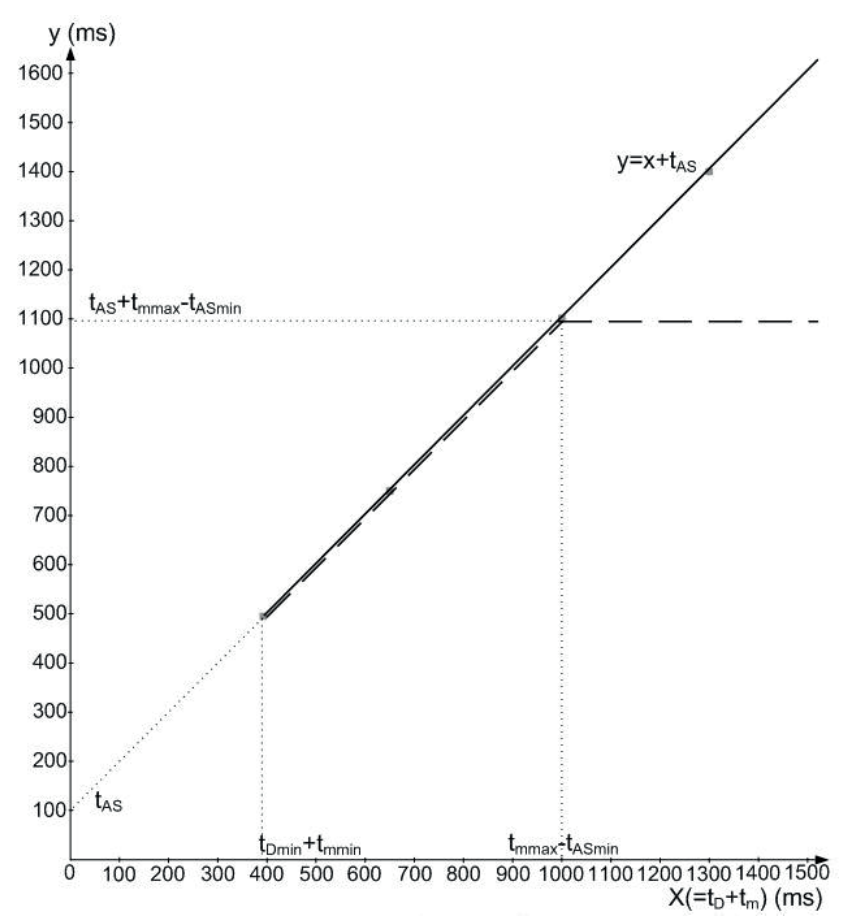

ista kašnjenja kao i u slučaju slanja pomoću dva odvojena kôda događaja. Ovakvo slanje sa jednim kôdom događaja je jednostavnije nego slanje sa dva kôda događaja, tako da ga treba primenjivati kada se dobijaju ista kašnjenja za oba postupka slanja.

U Tabeli 2 prikazan je potreban kapacitet za slanje CID poruke preko Interneta, u poređenju sa načinom slanja gde se vrši kodovanje odbiraka CID signala po A-zakonu kodovanja [8]. Potreban kapacitet za slučaj kodovanja odbiraka CID signala dat je za različite vremenske intervale paketizovanja CID signala $(10 \mathrm{~ms}, 20 \mathrm{~ms}$ i $30 \mathrm{~ms}$, odnosno 80,160 i 240 odbiraka signala u jednom paketu). U poslednjoj koloni dat je potreban kapacitet za slanje poruke po novom formatu kodovanjem jednim kôdom događaja. Poređenje je dato za tri slučaja identifikacije broja pozivajućeg pretplatnika: kada se pretplatnički broj sastoji od 6 cifara, kada se sastoji od 14 cifara i kada se šalje poruka identifikacije najveće predviđene dužine 75 byte-a.

TABELA 2 POTREBAN KAPACITET ZA SLANJE CID SIGNALA PREKO INTERNETA

Sl. $2 \mathrm{a}$

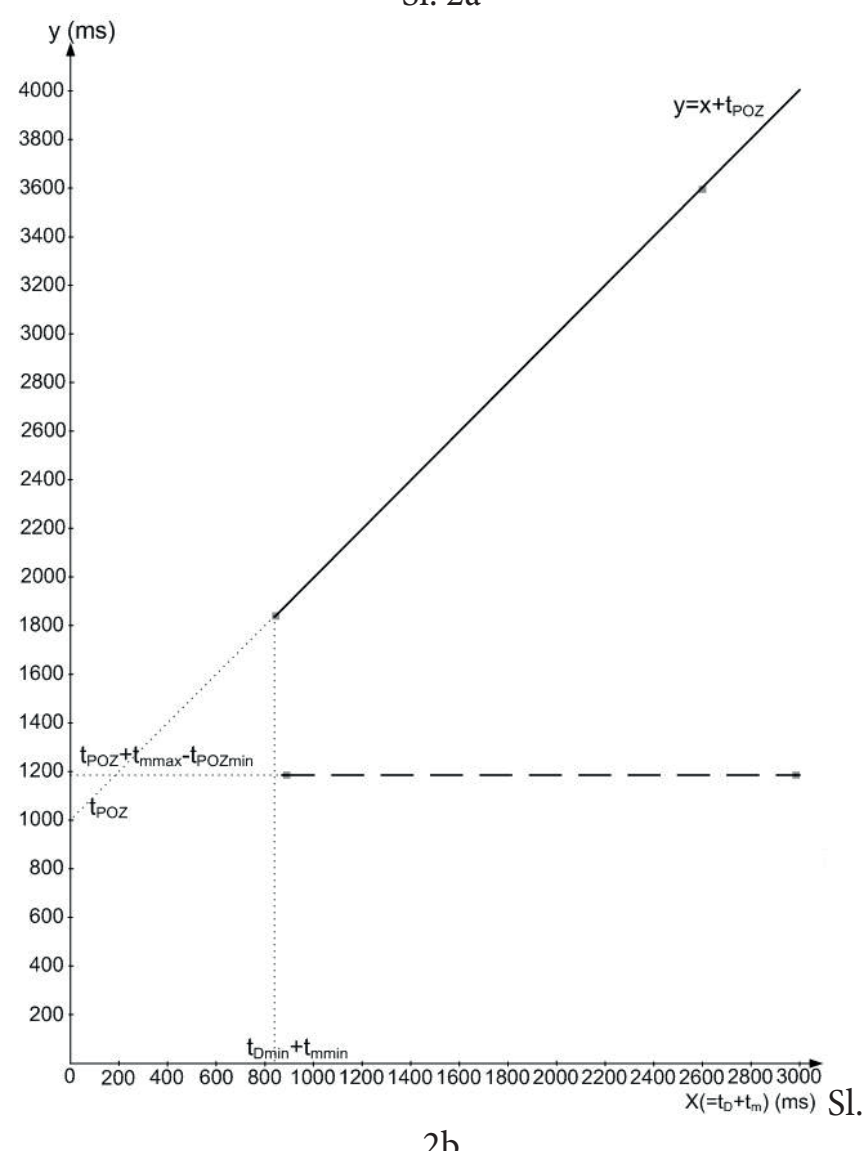

\begin{tabular}{|c|c|c|c|c|}
\hline \multirow{2}{*}{ Metod } & \multicolumn{3}{|c|}{$\begin{array}{l}\text { Kapacitet za kodovanje po A- } \\
\text { zakonu kompresije (bit) }\end{array}$} & \multirow{2}{*}{$\begin{array}{c}\text { Novi } \\
\text { postupak } \\
\text { (bit) }\end{array}$} \\
\hline & $10 \mathrm{~ms}$ & $20 \mathrm{~ms}$ & $30 \mathrm{~ms}$ & \\
\hline 6 cifara & 63720 & 51600 & 47200 & 640 \\
\hline 14 cifara & 70200 & 56760 & 51920 & 704 \\
\hline 75 byte-a & 114480 & 91160 & 84960 & 1044 \\
\hline
\end{tabular}

Sl. 2. Kašnjenja u reprodukciji CID signala

Posmatrajući vremena kašnjenja u reprodukciji CID signala korišćenjem jednog i dva kôda događaja, može se zaključiti da u slučaju slanja CID signala pridruženog pozivu treba težiti, kad god je moguće, da se koriste dva odvojena kôda događaja za poziv i CID, jer se dobijaju manja kašnjenja. U slučaju slanja zajedno sa alerting signalom, treba težiti slanju sa zajedničkim kôdom događaja za AS i CID. Naime, za slučaj kraćih CID poruka, koje se javljaju daleko češće nego dugačke poruke, dobijaju se

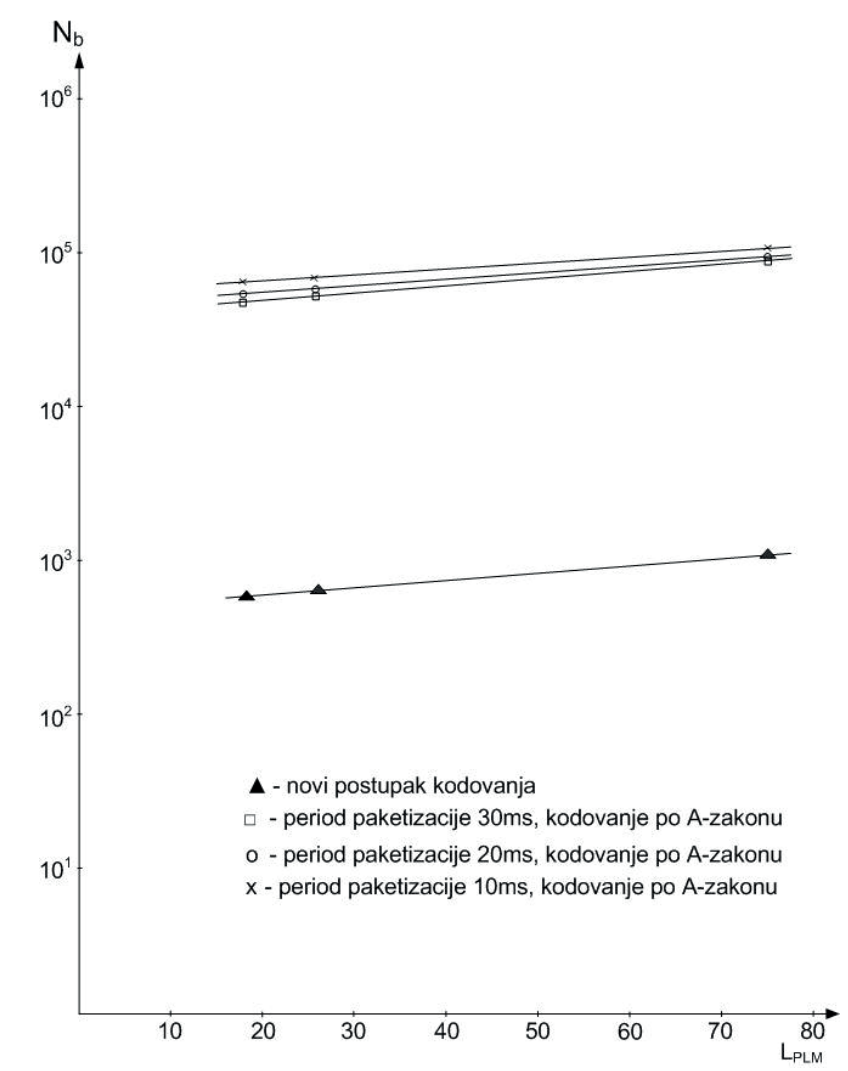

Sl. 3. Potreban broj bita za slanje CID signala 


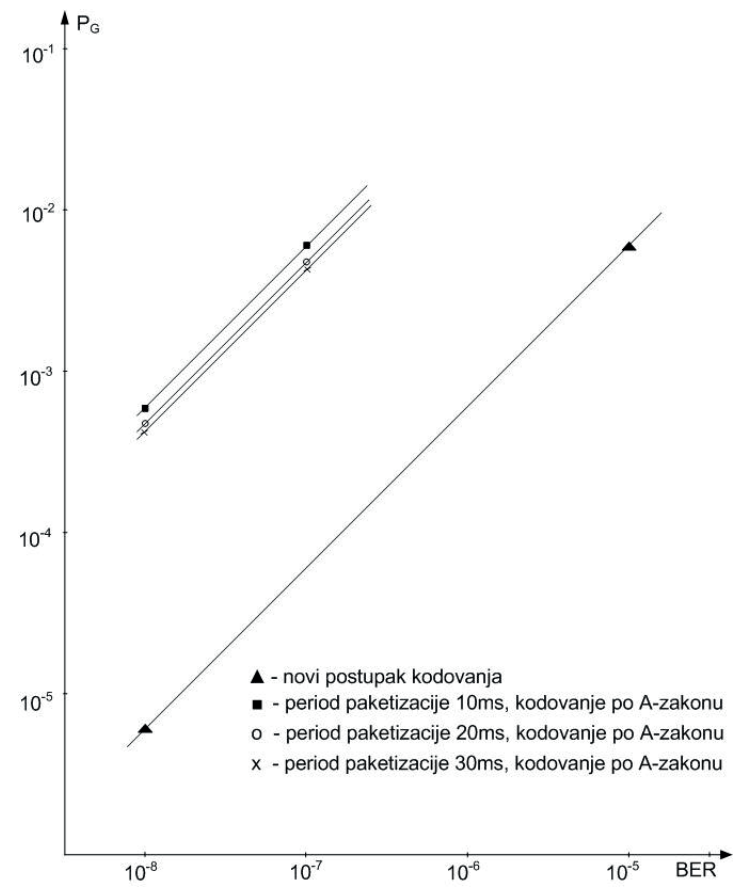

Sl. 4. Verovatnoća greške u prenosu CID signala

U slučaju primene prikazanog novog postupka za prenos CID signala preko Interneta postiže se značajno smanjenje potrebnog kapaciteta. Potrebni kapacitet nalazi se u granicama $1-1,5 \%$ od kapaciteta potrebnog za prenos odbiraka CID signala kodovanih po A-zakonu.

$\mathrm{Na}$ Sl.3, prikazani su grafički rezultati poređenja potrebnog broja bita $\left(\mathrm{N}_{\mathrm{b}}\right)$ za slanje CID signala u slučaju primene novog postupka i u slučaju kodovanja po A-zakonu sa periodom paketizacije $10 \mathrm{~ms}, 20 \mathrm{~ms}$ i $30 \mathrm{~ms}$. Rezultati su prikazani u funkciji dužine (L) korisnog sadržaja CID poruke, izražene u broju bajta (Presentation Layer Message - PLM) [6].

Značajno smanjenje potrebnog kapaciteta za prenos CID poruke preko Interneta povlači i značajno smanjenje verovatnoće greške $\left(\mathrm{P}_{\mathrm{G}}\right)$ u prenosu CID signala. Dobijeni rezultati prikazani su na Sl.4, u funkciji verovatnoće greške bita (Bit Error Rate - BER).

\section{ZAKLJUČAK}

U ovom radu prikazuju se specifičnosti primene Interneta kao medija koji omogućava ostvarivanje govornih telefonskih veza pretplatnika u ruralnim oblastima, gde ne postoji razvijena telekomunikaciona infrastruktura (gde kablovska mreža nije postavljena i gde nema telefonskih centrala). U tom slučaju Internet omogućava premošćavanje velikih prostora bez telefonskih veza, da bi se veza vratila u svoj telefonski oblik na mestu gde za to postoje uslovi. Prikazano je nekoliko scenarija kako se ovakva funkcija Interneta može realizovati. Poseban akcenat dat je scenariju gde Internet služi za paketizaciju signala na pretplatničkoj telefonskoj liniji. Time je pokazano da je moguća ovakva primena Interneta u nerazvijenim zemljama ili nerazvijenim regijama.

Značajan element u ostvarivanju ovakve funkcije predstavlja način kako se šalju telefonski signalizacioni kriterijumi preko Interneta. Rad prikazuje kako se signalizacija šalje preko Interneta i kako se mogu uneti izmene u postupak slanja signala identifikacije pozivajućeg pretplatnika da se ovo slanje pojednostavi, da se smanji potreban kapacitet za slanje signala i, samim tim, smanji verovatnoća greške u slanju.

\section{LITERATURA}

[1] Ž. Markov, "Savremena telefonska tehnika (600 pitanja i odgovora)," IRITEL, 2005.

[2] A. Dutta-Roy, "Fixed Wireless Routes for Internet Access," IEEE Spectrum, vol. 36, Issue 9, pp. 61-69, September 1999.

[3] H. Schulzrinne, T. Taylor: "RFC 4733: RTP Payload for DTMF Digits, Telephony Tones, and Telephony Signals", December 2006.

[4] H. Schulzrinne, T. Taylor: "RFC 4734: Definition of Events for Modem, Fax, and Text Telephony Signals", December 2006.

[5] H. Schulzrinne, T. Taylor: "RFC5244: Definition of Events For Channel-Oriented Telephony Signalling”, June 2008.

[6] ETSI EN 300 659-1 V1.3.1: "Access and Terminals (AT); Analogue access to the Public Switched Telephone Network (PSTN); Subscriber line protocol over the local loop for display (and related) services; Part 1: On hook data transmission", 2001-01.

[7] ETSI EN 300 659-2 V1.3.1: "Access and Terminals (AT); Analogue access to the Public Switched Telephone Network (PSTN); Subscriber line protocol over the local loop for display (and related) services; Part 2: Off- hook data transmission", 2001-01.

[8] A. Lebl: "Prilozi razvoju tehnologije prenosa telefonske signalizacije preko Interneta," doktorska disertacija, Univerzitet u Novom Sadu, FTN Novi Sad, Jun 2009.

\section{USAGE OF INTERNET IN COMMUNICATION OF TELEPHONE USERS IN RURAL AREAS - MODIFICATION OF METHOD FOR SIGNALLING TRANSMISSION}

\section{Abstract:}

The paper presents how Internet can be used to realize speech communication between telephone users in the areas without developed telecommunication infrastructure. The methods of telephone signal transmission over Internet, specially the methods of telephone signalling transmission, are analyzed. At the end it is presented how the method for transmission of caller identification over Internet is improved comparing to the possibilities allowed by Internet recommendations. The characteristics of the new method are analyzed considering the transmission delay, the bandwidth necessary to transmit the signal over Internet and the transmission error probability.

\section{Key words:}

Telephone Users,

Rural Areas,

Telephone Signalling,

Gateway,

Caller Identification. 